Research Article

\title{
Cytokines in Preterm Delivery: Proposal of a New Diagnostic Algorithm
}

\author{
Grzegorz Raba $\mathbb{D D}^{1,2}$ and Jacek Tabarkiewicz $\mathbb{D D}^{3,2}$ \\ ${ }^{1}$ Institute of Obstetric and Emergency Medicine, Faculty of Medicine, University of Rzeszow, Ul. Pigonia 6, 35-310 Rzeszów, Poland \\ ${ }^{2}$ Centre for Innovative Research in Medical and Natural Sciences', Faculty of Medicine, University of Rzeszow, Ul. Warzywna 1a, \\ 35-959 Rzeszów, Poland \\ ${ }^{3}$ Department of Human Immunology, Faculty of Medicine, University of Rzeszow, Al. Mjr. W. Kopisto 2a, 35-310 Rzeszów, Poland
}

Correspondence should be addressed to Grzegorz Raba; rabagrzegorz@gmail.com

Received 9 August 2017; Revised 1 December 2017; Accepted 15 December 2017; Published 8 April 2018

Academic Editor: Stuart Berzins

Copyright (c) 2018 Grzegorz Raba and Jacek Tabarkiewicz. This is an open access article distributed under the Creative Commons Attribution License, which permits unrestricted use, distribution, and reproduction in any medium, provided the original work is properly cited.

\begin{abstract}
Predicting preterm delivery within 7 days is very important for the proper timing of glucocorticosteroid administration. If within 7 days after glucocorticosteroid administration, the delivery does not occur, it remains questionable if repeated glucocorticosteroid therapy results in improved infant respiratory function. Therefore, differentiation of preterm delivery from false preterm delivery is clinically significant. The aim of this study was to create a diagnostic algorithm to distinguish preterm delivery from false preterm delivery on the basis of concentrations of selected cytokines. The study group $(n=622)$ were patients hospitalized due to threatened preterm delivery. To assess the concentration of cytokines in the serum, we used a multiplex method, which allows simultaneous determination of 13 cytokines. The sets consist of the following cytokines: IGFBP-1, IGFBP-2, BDNF, L-Selectin, E-Selectin, ICAM-1, PECAM, VCAM-1, MIP-1d, MIP-3b, Eotaxin-1, Eotaxin-2, and BLC. In the study group, $67.8 \%$ patients had preterm delivery and $32.2 \%$ had false preterm delivery. Based on the analysis of cytokine concentrations, a classification tree to distinguish between preterm delivery and false preterm delivery was created. Our findings show the possibility of prediction of preterm delivery with the use of a classification and regression tree of selected cytokine concentration.
\end{abstract}

\section{Introduction}

Preterm birth (PTB), defined as birth prior to 37 weeks of gestation, affects $5-18 \%$ of pregnancies and is appraised to be the leading cause of neonatal death and the second cause of childhood death below the age of 5 years. The uterine overdistention, cervical diseases, breakdown of maternal-fetal tolerance, decidual senescence, vascular disorders, infections, and stress are the major mechanisms of the disease implicated in spontaneous preterm labor, but probably there are still unknown factors included in this pathology [1]. Physical activity has been theoretically related to PTB because it increases the release of catecholamines, for example, norepinephrine, which might stimulate myometrial activity. On the other hand, Mascio et al. showed that aerobic exercise can be safely performed by normal-weight women with singleton, uncomplicated gestations because this is not associated with an increased risk of preterm birth or with a reduction in mean gestational age at delivery [2]. The prevention of preterm birth by use of special diet or diet supplements, for example, omega-3 supplementation during pregnancy, does not reduce the incidence of PTB birth or improve neonatal outcome [3]. The goal of preterm delivery treatment is to reduce the effects of prematurity in a newborn. Based on an individual patient data, meta-analysis cerclage cannot currently be recommended for clinical use especially in twin pregnancies with a maternal short cervical length in the second trimester, because there are no statistically significant differences in primary and secondary outcomes [4]. According to data from The American Congress of Obstetricians and Gynecologists (ACOG), the factor that improves the prognosis for premature infants is not the delay of delivery 
but glucocorticosteroid administration within 7 days prior to delivery in order to improve respiratory function in the newborn [5]. On average, tocolytic treatment prolongs the duration of pregnancy by only 48 hours [6]. It is a short period, slightly increasing child maturity; however, this time period makes it possible to administer glucocorticosteroids to the mother, increasing the amount of surfactant in the newborn's alveoli and reducing the incidence and severity of respiratory distress syndrome (RDS) [7-10]. Gaining time to administer glucocorticosteroids to a woman at risk for preterm delivery is the main indication for tocolytic treatment. Improvement in lung respiratory function is maintained in a child for a period of around 7 days after administration of glucocorticosteroids to the mother $[11,12]$. If there is no delivery within 7 days after steroid administration, it remains disputable whether repeated steroid therapy during the same pregnancy brings similar benefits of improvement in an infant's respiratory function [13].

Therefore, the decision to administer glucocorticosteroids in the treatment of women with threatened preterm delivery should be made if the probability of delivery in a period shorter than 7 days is thought to be small. This is difficult in clinical practice because currently there are no accurate diagnostic markers that allow for sensitive and specific differentiation of early preterm delivery from false preterm delivery. There are models of differential diagnosis of early preterm delivery and false preterm delivery based on the identification of risk factors [14]; however, in some cases, estimation of these risk factors is not possible. With the development of molecular biology techniques, great hopes lie in research on the identification of markers allowing for differentiation of early preterm delivery from false preterm delivery. It is indispensable for the proper timing of glucocorticosteroid application in a pregnant woman in order to improve respiratory function in a newborn. Varied etiopathogenesis of preterm delivery resulted from the fact that in the past decade identification of numerous cytokines and molecules connected with preterm delivery has not brought any significant progress in the differential diagnosis of early preterm delivery and false preterm delivery. The majority of the commercially available tests is based on the estimation of insulin-like growth factor binding protein (IGFBP-1) in combination with other molecules, for example, alpha-fetoprotein (AFP) or interleukin 6 (IL-6) [15-18]. Additionally, a majority of these immunoassays are used for detection and confirmation of fetal membrane rupture. Some methods, for example, fetal fibronectin testing in singleton gestations with threatened preterm labor, are associated with higher costs, but not with the prevention of preterm birth or improvement in perinatal outcome [19]. The complex pathogenesis of preterm labor authorizes the undertaking of trials to create multifactorial models that take into account the interactions and interrelationship of cytokines. In our study, we estimated serum concentrations of IGFBP-1 and twelve other markers and their usefulness for differentiation of preterm delivery from false preterm delivery. To the best of our knowledge, the majority of these markers is estimated on a large cohort of patients for the first time. The choice of these thirteen cytokines was justified by their potential role in inflammation processes involved in the pathogenesis of preterm delivery. IGFBP-1 and IGFBP-2 help to lengthen the half-life of circulating IGFs in all tissues and alter their interaction with cell surface receptors. Pregnant women who are in preterm labor with intact fetal membranes and who have a positive IGFBP-1 test result in cervical secretion have an increased risk of preterm delivery [20]. BDNF binds carboxypeptidase E (CPE), and the disruption of this binding has been proposed to cause the loss of sorting into densecore vesicles. It may be involved in the pathogenesis of PD by modulating the activity of neurotransmitter receptors, including the alpha-7 nicotinic receptor. Nicotinic receptors are involved in direct and endocrine effects on the main processes of placental development [21]. L-Selectin is a molecule found on lymphocytes and the preimplantation embryo acting as a "homing receptor" for lymphocytes to enter secondary lymphoid tissues via high endothelial venules. It may be involved in the pathogenesis of PD by modulating the inflammation process [22]. E-Selectin during inflammation plays an important part in recruiting leukocytes to the site of injury, and its potential role in the pathogenesis of PD was described [22]. ICAM-1 is a type of intercellular adhesion molecule continuously present in low concentrations in the membranes of leukocytes and plays a role in spermatogenesis [23]. PECAM plays a key role in removing aged neutrophils from the body and is likely involved in leukocyte transmigration, which has a potential role in the pathogenesis of PD [24]. VCAM-1 mediates the adhesion of lymphocytes, monocytes, eosinophils, and basophils to the vascular endothelium and is responsible for fetal growth restriction and PD [25]. MIP-1d is chemotactic for neutrophils, monocytes, and lymphocytes and elicits its effects by binding to cell surface chemokine receptors. The role in the pathogenesis of PD was evaluated in recent studies [26]. MIP-3b may play a role in normal lymphocyte recirculation and homing. It also plays an important role in $\mathrm{T}$ cell and $\mathrm{B}$ cell migration to secondary lymphoid organs. The role in the pathogenesis of PD was evaluated in recent studies [26]. Eotaxin-1 selectively recruits eosinophils by inducing their chemotaxis, which has a potential role in the pathogenesis of $\mathrm{PD}$ by modulating the inflammation process [27]. Eotaxin-2 is strongly chemotactic for resting $\mathrm{T}$ lymphocytes and slightly chemotactic for neutrophils [27]. BLC is selectively chemotactic for B cells belonging to both the B-1 and B-2 subsets and elicits its effects by interacting with chemokine receptor CXCR5. The role in the pathogenesis of $\mathrm{PD}$ was evaluated in recent studies [26].

The aim of this study was to create a diagnostic algorithm differentiating preterm delivery from false preterm delivery on the basis of concentrations and interactions of chosen serum markers.

\section{Materials and Methods}

The study group consisted of 622 pregnant women hospitalized due to threatened preterm delivery. The consent to perform the study was obtained from the local bioethics committee. The diagnosis of threatened preterm delivery 
TABLE 1: Characteristic of the groups.

\begin{tabular}{|c|c|c|c|c|}
\hline Parameter & Statistics & Preterm delivery & False preterm delivery & $p$ \\
\hline \multirow{3}{*}{ Maternal age (years) } & \multirow{2}{*}{ Mean \pm SEM } & 26.4 & 25.1 & \multirow{3}{*}{0.241} \\
\hline & & 5.22 & 5.62 & \\
\hline & Min-max & $16-41$ & $18-39$ & \\
\hline \multirow{3}{*}{ Gravidity } & \multirow{2}{*}{ Mean \pm SEM } & 2 & 1.8 & \multirow{3}{*}{0.112} \\
\hline & & 1.04 & 1.18 & \\
\hline & Min-max & $1-6$ & $1-4$ & \\
\hline \multirow{3}{*}{ Gestational age (weeks) } & \multirow{2}{*}{ Mean \pm SEM } & 31.1 & 28.3 & \multirow{3}{*}{0.068} \\
\hline & & 3.96 & 5.9 & \\
\hline & Min-max & $22-36$ & $23-36$ & \\
\hline \multirow{3}{*}{ Fetal weight by USG examination } & \multirow{2}{*}{ Mean \pm SEM } & 1761 & 1642 & \multirow{3}{*}{0.136} \\
\hline & & 658 & 757 & \\
\hline & Min-max & $507-2482$ & $612-2420$ & \\
\hline \multirow{3}{*}{ Maternal height $(\mathrm{cm})$} & \multirow{2}{*}{ Mean \pm SEM } & 162.5 & 164.2 & \multirow{3}{*}{0.231} \\
\hline & & 5.98 & 8.18 & \\
\hline & Min-max & $150-175$ & $153-181$ & \\
\hline \multirow{3}{*}{ Maternal weight (kg) } & \multirow{2}{*}{ Mean \pm SEM } & 66.1 & 61.1 & \multirow{3}{*}{0.083} \\
\hline & & 12.18 & 15.5 & \\
\hline & Min-max & $47-99$ & $52-94$ & \\
\hline \multirow{3}{*}{ Maternal weight before pregnancy $(\mathrm{kg})$} & \multirow{2}{*}{ Mean \pm SEM } & 57.9 & 54.4 & \multirow{3}{*}{0.061} \\
\hline & & 10.47 & 14.2 & \\
\hline & Min-max & $42-90$ & $45-79$ & \\
\hline \multirow{3}{*}{ Vaginal $\mathrm{pH}$} & \multirow{2}{*}{ Mean \pm SEM } & 5.4 & 5.3 & \multirow{3}{*}{0.133} \\
\hline & & 0.84 & 1.23 & \\
\hline & Min-max & $4.2-7.2$ & $4.2-5.9$ & \\
\hline \multirow{3}{*}{ Blood hemoglobin (g/dl) } & \multirow{2}{*}{ Mean \pm SEM } & 11.6 & 11.2 & \multirow{3}{*}{0.074} \\
\hline & & 0.84 & 1.12 & \\
\hline & Min-max & $9.8-13.8$ & $10.2-14.1$ & \\
\hline \multirow{3}{*}{$\mathrm{WBC}\left(\mathrm{mm}^{3}\right)$} & \multirow{2}{*}{ Mean \pm SEM } & 7271 & 6830 & \multirow{3}{*}{0.212} \\
\hline & & 638.55 & 594.8 & \\
\hline & Min-max & $5340-26,000$ & $4800-14,000$ & \\
\hline
\end{tabular}

was based on clinical criteria by Czajka et al. [28]. We excluded patients

(i) With clinical signs of infection

(ii) Who were treated with antibiotics up to 3 weeks before the study

(iii) With placenta previa

(iv) With placental abruption

(v) With multiple pregnancies

(vi) With cervical incompetence

After the diagnosis was made, all patients were tested for concentrations of the analyzed markers, after which they were treated according to a single tocolytic procedure with the use of intravenous fenoterol infusion $0.05 \mathrm{mg} /$ hour during 48 hours along with glucocorticosteroid therapy ( 2 doses of betamethasone $12 \mathrm{mg}$ every 24 hours). According to the guidelines [6-8], after treatment, the patients were prepared for preterm birth. Peripheral blood samples were collected into a serum separating tube (Becton Dickinson, USA; Barricore tube with mechanical separator and lithium heparin for plasma separation) and after centrifugation with the use $1000 \times \mathrm{g}$ for $5 \mathrm{~min}$. at temperature $4^{\circ} \mathrm{C}$ and serum separation, samples were aliquoted and cryopreserved at $-86^{\circ} \mathrm{C}$. Concentration of selected markers was measured in the laboratory of RayBiotech, Norcross, GA, USA, with the use of Quantibody ${ }^{\circledR}$ Human Cytokine Array 1 Kit. Samples were transported in certified packages on dry ice. We determined concentrations of markers, which could be grouped into the following clusters:

(1) Circulating proteins variably expressed during inflammatory phase: IGFBP-1, IGFBP-2, and BDNF

(2) Adhesion molecules involved in leukocyteendothelial transduction: L-Selectin, E-Selectin, ICAM-1, PECAM, and VCAM-1 
TABle 2: Comparison of concentration levels of the analyzed markers between preterm delivery and false preterm delivery groups.

\begin{tabular}{lccccc}
\hline & \multicolumn{2}{c}{ Preterm delivery } & \multicolumn{3}{c}{ False preterm delivery } \\
& Mean $(\mathrm{pg} / \mathrm{ml})$ & \pm SEM & Mean $(\mathrm{pg} / \mathrm{ml})$ & \pm SEM & $p$ \\
\hline BDNF & 49.41 & 4.10 & 31.87 & 2.33 & 0.004 \\
BLC & 45.28 & 5.69 & 22.75 & 2.42 & 0.005 \\
Eotaxin-1 & 1.68 & 0.16 & 1.03 & 0.08 & 0.001 \\
Eotaxin-2 & 9.37 & 0.08 & 9.21 & 1.36 & 0.607 \\
E-Selectin & 393.43 & 29.80 & 372.55 & 32.41 & 0.953 \\
ICAM-1 & 502.77 & 42.30 & 459.14 & 33.20 & 0.699 \\
IGFBP-1 & 177.97 & 41.57 & 144.57 & 33.35 & 0.001 \\
IGFBP-2 & 429.72 & 65.63 & 424.00 & 34.55 & 0.695 \\
L-Selectin & 2369.2 & 318.13 & 2379.9 & 265.01 & 0.888 \\
MIP-1d & 25.01 & 6.63 & 27.79 & 6.10 & 0.092 \\
MIP-3b & 31.16 & 5.19 & 24.22 & 4.75 & 0.93 \\
PECAM-1 & 27.94 & 12.03 & 31.78 & 17.66 & 0.248 \\
VCAM-1 & 44.87 & 20.44 & 36.09 & 10.46 & 0.158 \\
\hline
\end{tabular}

(3) Chemokines: MIP-1d, MIP-3b, Eotaxin-1, Eotaxin-2, and BLC

The results were compared with the final time of delivery. Preterm delivery was diagnosed in those pregnant women who had delivery within 7 days of administration of tocolytic treatment and glucocorticosteroid therapy. The final diagnosis of false preterm delivery depended on the stopping of contractions and occurrence of delivery after a period longer than 7 days since the completion of glucocorticosteroid treatment.

Discriminant analysis by standard and forward stepwise selection method included 13 proteins, of which changes in serum concentrations in women at risk for preterm delivery have been proved in many studies $[2,26,29,30]$. We used Statistica 8.0 PL (StatSoft, Poland) with StatSoft Statistica neural networks package. The obtained results of analyses were used to create a model of differential diagnosis between preterm delivery and false preterm delivery, on the basis of a classification and regression tree [31].

\section{Results}

In the study group of 622 patients at threatened preterm delivery, $422(67.8 \%)$ had preterm delivery in the period of a few hours to 7 days since the initiation of treatment. The remaining $200(32.2 \%)$ had false preterm delivery. There were no statistical differences between women with preterm delivery and false preterm delivery, and the characteristics of both groups are summarized in Table 1.

We analyzed 13 markers which could be associated with preterm delivery IGFBP-1, IGFBP-2, BDNF, L-Selectin, E-Selectin, ICAM-1, PECAM, VCAM-1, MIP-1d, MIP-3b, Eotaxin-1, Eotaxin-2, and BLC, and we estimated their usefulness as markers for differentiation between threatened preterm delivery, preterm delivery, and false
TABLE 3: Predictive values of selected markers marked with discriminant analysis by standard method.

\begin{tabular}{lcccccc}
\hline $\begin{array}{l}\text { Biochemical } \\
\text { marker }\end{array}$ & $\begin{array}{c}\text { Wilks's } \\
\text { lambda }\end{array}$ & $\begin{array}{c}\text { Partial } \\
\text { Wilks's }\end{array}$ & $F$ & $p$ & Tolerance & 1-toler \\
\hline BDNF & 0.636 & 0.891 & 5.733 & 0.021 & 0.851 & 0.148 \\
BLC & 0.601 & 0.943 & 2.840 & 0.099 & 0.796 & 0.204 \\
Eotaxin & 0.589 & 0.963 & 1.818 & 0.184 & 0.582 & 0.418 \\
Eotaxin-2 & 0.581 & 0.976 & 1.143 & 0.290 & 0.678 & 0.322 \\
E-Selectin & 0.571 & 0.993 & 0.332 & 0.567 & 0.393 & 0.607 \\
ICAM-1 & 0.577 & 0.983 & 0.815 & 0.371 & 0.661 & 0.339 \\
IGFBP-1 & 0.623 & 0.911 & 4.603 & 0.037 & 0.724 & 0.276 \\
IGFBP-2 & 0.567 & 0.100 & 0.001 & 0.995 & 0.512 & 0.487 \\
L-Selectin & 0.603 & 0.941 & 2.961 & 0.092 & 0.397 & 0.602 \\
MIP-1d & 0.567 & 0.100 & 0.004 & 0.951 & 0.691 & 0.309 \\
MIP-3b & 0.567 & 0.100 & 0.002 & 0.966 & 0.836 & 0.164 \\
PECAM-1 & 0.657 & 0.863 & 7.453 & 0.009 & 0.779 & 0.221 \\
VCAM-1 & 0.571 & 0.993 & 0.336 & 0.565 & 0.634 & 0.366 \\
\hline
\end{tabular}

TABle 4: Predictive value of selected markers marked with discriminant analysis by stepwise forward selection method.

\begin{tabular}{lcccccc}
\hline $\begin{array}{l}\text { Biochemical } \\
\text { marker }\end{array}$ & $\begin{array}{c}\text { Wilks's } \\
\text { lambda }\end{array}$ & $\begin{array}{c}\text { Partial } \\
\text { Wilks's }\end{array}$ & $F$ & $p$ & Tolerance & 1-toler \\
\hline IGFBP-1 & 0.668 & 0.891 & 6.447 & 0.014 & 0.813 & 0.187 \\
PECAM-1 & 0.687 & 0.867 & 8.103 & 0.006 & 0.864 & 0.136 \\
Eotaxin-1 & 0.617 & 0.965 & 1.917 & 0.172 & 0.846 & 0.154 \\
BDNF & 0.657 & 0.907 & 5.460 & 0.023 & 0.938 & 0.062 \\
BLC & 0.641 & 0.930 & 3.987 & 0.050 & 0.887 & 0.113 \\
L-Selectin & 0.627 & 0.950 & 2.784 & 0.101 & 0.767 & 0.233 \\
VCAM-1 & 0.611 & 0.976 & 1.327 & 0.254 & 0.867 & 0.133 \\
Eotaxin-2 & 0.586 & 0.983 & 0.904 & 0.346 & 0.737 & 0.263 \\
E-Selectin & 0.590 & 0.990 & 0.501 & 0.482 & 0.437 & 0.563 \\
ICAM-1 & 0.586 & 0.984 & 0.844 & 0.362 & 0.859 & 0.141 \\
IGFBP-2 & 0.596 & 0.100 & 0.008 & 0.931 & 0.773 & 0.227 \\
MIP-1d & 0.594 & 0.997 & 0.136 & 0.713 & 0.830 & 0.170 \\
MIP-3b & 0.596 & 0.100 & 0.003 & 0.959 & 0.908 & 0.092 \\
\hline
\end{tabular}

preterm delivery. The concentrations of the analyzed parameters are shown in Table 2. Due to the relatively low number of statistically significant differences in simple comparison between the two groups, we decided to perform more complex analysis. The results of the discriminant analysis are summarized in Tables 3 and 4 . We found that 7 of the markers examined are significantly associated with preterm labor: IGFBP-1, BDNF, ICAM-1, VCAM-1, MIP-1d, MIP-3b, and BLC. We calculated cutoff points for these molecules with the use of ROC and chose those with the highest sensitivity and specificity. Based on predictive value and association with preterm delivery, we propose an algorithm for the differentiation of threatened preterm delivery, preterm delivery, and false preterm delivery as shown in Figure 1. 




FIGURE 1: Diagnostic model to differentiate preterm delivery from false preterm delivery on the basis of biochemical markers concentrations. TPD: threatened preterm delivery; PD: preterm delivery; FPD: false preterm delivery.

\section{Discussion}

The variation in cytokine correlation levels of many cytokines with preterm delivery $[32,33]$ suggests that the immune response is more complex and depends on many factors. Therefore, attempts to predict preterm delivery based on the concentrations of individual biochemical markers are not effective. In the present study, we developed a novel diagnostic model differentiating preterm delivery from false preterm delivery based on a classification tree.

Due to the multifactorial aetiology of preterm delivery, only joint interpretation of the concentrations of numerous groups of cytokines, taking into account their relative interactions, can be useful in predicting preterm delivery. The successes of the reductionist approach, based on a priori hypotheses, limit the possibilities of applying systemic information. New methodologies based on frameworks for simultaneous measurement of various factors seem to effectively displace the previously used univariate reductionist approach. This is particularly important in the context of complex systemic diseases such as preterm delivery. According to Laudanski et al. [34], reduction from general to particular can marginalize the role of other unexpected causative agents. A systemic approach, which allows for making hypotheses based on the multifactorial aetiology of the problem, seems to be better suited to research on preterm delivery. In certain cases, chronic immune reaction can lead to a weakened response, demonstrated by the reduction of concentrations of some cytokines. Therefore, in the diagnosis of preterm delivery, assessment of the relative proportions of individual biochemical markers is more important than searching for values of their cutoff thresholds as particular biochemical markers. In women with vaginal colonization with anaerobic bacteria at 18-22 weeks of gestation, distortion in the proportion between the concentration of IL-1 $\beta$ and IL-1Ra (receptor IL-1 antagonist) [35] has been demonstrated. An elevated level of IL- $1 \beta$ and reduced levels of IL$1 \mathrm{Ra}$ allowed for the identification of women at high risk of preterm delivery. Zhang et al. presented results proving that low VCAM-1 expression in the trophoblastic cell could be correlated to the pathogenesis and progression of gestational hypertension (GH) [25]. The gestational hypotension could be associated with preterm delivery, and we found that serum level of VCAM-1 is one of the factors in differentiating FPD and PD. Mešić Đogić et al. and Eleje et al. showed that elevated concentration of IGFBP1 in cervical secretion were highly correlated with preterm labor [17]. In our study, we showed that also serum concentration of IGFBP1 could be used in algorithm differentiating PD, TPD, and FPD. The chemokines including CCL20 (MIP-3a) may play a role in the pathogenesis of preterm labor [27]. In our study, we found that other members of the chemokine family as MIP$3 \mathrm{~b}$ and MIP-1d could be associated with preterm delivery. Identification of a single biomarker to predict spontaneous PD delivery poses a significant challenge due to the miscellany of clinical presentations and of the pathomechanisms involved in preterm birth. The presented multifactorial diagnostic model based on a classification tree makes verification of patients at threatened preterm delivery and prediction of delivery within 7 days simple and quick. This has a very important clinical significance as it helps in choosing the proper timing of glucocorticosteroid therapy in pregnant women in order to improve the respiratory function of the newborn. Application of glucocorticosteroids within 7 days before the onset of preterm delivery is currently the most effective method of improving perinatal results in preterm delivery [36]. Contrary to commercially available immunoassay tests, for example, ROM Plus ${ }^{\circledR}$ and AmniSure ${ }^{\circledR}$, which are used for diagnosis of preterm membrane rupture (pPROM) [16], our algorithm could be used not only for confirmation of preterm delivery started as a subclinical pPROM but also for support of decision-making for the administration of glucocorticosteroids. The disadvantage of the presented system of differential diagnosis of preterm delivery and false preterm delivery is its novel character, as well as the small group covered by the study in a single-center research model. However, the results obtained in the period of 4 years in this group of 622 patients are encouraging and justify additional testing. The publication in this paper of a complete algorithm diagram for the diagnosis of preterm delivery means 
the author grants his permission for its use in both practice and for research purposes. Verification of the presented diagnostic model in other centers and in other populations would be of high educational value. Easy interpretation of results by means of the presented classification tree encourages such attempts.

\section{Conclusions}

Our findings show the possibility of predicting preterm delivery within 7 days using a classification and regression tree of concentrations of selected cytokines. Our algorithm is not restricted only for conditions like rupture of membranes but could also support the decision of treatment with glucocorticosteroids in patients who will deliver a baby within 7 days. Additionally, it could help to make the decision of treatment postponement in patients with a high probability that delivery would be later than 7 days from glucocorticosteroid administration.

\section{Abbreviations}

IGFBP-1: Insulin-like growth factor-binding protein 1 IGFBP-2: Insulin-like growth factor-binding protein 2 BDNF: Brain-derived neurotrophic factor

L-Selectin: CD62L

E-Selectin: CD62E

ICAM-1: Intercellular adhesion molecule 1

PECAM: Platelet endothelial cell adhesion molecule

VCAM-1: Vascular cell adhesion protein 1

MIP-1d: Chemokine (C-C motif) ligand 15 (CCL15)

MIP-3b: Macrophage inflammatory protein-3 (CCL19)

Eotaxin-1: C-C motif chemokine 11 (CCL11)

Eotaxin-2: Chemokine (C-C motif) ligand 24 (CCL24)

BLC: $\quad$ B lymphocyte chemoattractant.

\section{Conflicts of Interest}

The authors declare that they have no conflicts of interest.

\section{Acknowledgments}

The authors would like to thank Dr. David Aebisher for linguistic editing.

\section{References}

[1] R. Romero, S. K. Dey, and S. J. Fisher, "Preterm labor: one syndrome, many causes," Science, vol. 345, no. 6198, pp. 760-765, 2014.

[2] D. Di Mascio, E. R. Magro-Malosso, G. Saccone, G. D. Marhefka, and V. Berghella, "Exercise during pregnancy in normalweight women and risk of preterm birth: a systematic review and meta-analysis of randomized controlled trials," American Journal of Obstetrics and Gynecology, vol. 215, no. 5, pp. 561-571, 2016.

[3] G. Saccone and V. Berghella, "Omega-3 long chain polyunsaturated fatty acids to prevent preterm birth: a systematic review and meta-analysis," Obstetrics and Gynecology, vol. 125, no. 3, pp. 663-672, 2015.
[4] G. Saccone, O. Rust, S. Althuisius, A. Roman, and V. Berghella, "Cerclage for short cervix in twin pregnancies: systematic review and meta-analysis of randomized trials using individual patient-level data," Acta Obstetricia et Gynecologica Scandinavica, vol. 94, no. 4, pp. 352-358, 2015.

[5] J. A. Bastek, M. D. Sammel, S. K. Srinivas et al., "Clinical prediction rules for preterm birth in patients presenting with preterm labor," Obstetrics and Gynecology, vol. 119, no. 6, pp. 1119-1128, 2012.

[6] G. Kayem, E. Lorthe, and M. Doret, "Prise en charge d'une menace d'accouchement prématuré," Journal de Gynécologie, Obstétrique et Biologie de la Reproduction, vol. 45, no. 10, pp. 1364-1373, 2016.

[7] C. Lyon and J. K. Bello, "Steroids during late preterm labor: better later than never," The Journal of Family Practice, vol. 66, no. 2, pp. 104-106, 2017.

[8] R. J. Freitas, T. N. Munhoz, I. da Silva dos Santos et al., "Providers' compliance with practice guidelines of prenatal and neonatal care to reduce neonatal mortality: 2004 versus 2012," Revista Brasileira de Epidemiologia, vol. 19, no. 4, pp. 702-712, 2016.

[9] A. S. Morgan, N. Marlow, E. S. Draper, Z. Alfirević, E. M. Hennessy, and K. Costeloe, "Impact of obstetric interventions on condition at birth in extremely preterm babies: evidence from a national cohort study," BMC Pregnancy and Childbirth, vol. 16, no. 1, p. 390, 2016.

[10] B. K. Jordan, D. Schilling, and C. T. McEvoy, "Pulmonary function at hospital discharge in preterm infants randomized to a single rescue course of antenatal steroids," The Journal of Pediatrics, vol. 181, pp. 62-66.e1, 2017.

[11] G. Saccone and V. Berghella, "Antenatal corticosteroids for maturity of term or near term fetuses: systematic review and meta-analysis of randomized controlled trials," BMJ, vol. 355, article i5044, 2016.

[12] D. G. Sweet, V. Carnielli, G. Greisen et al., "European Consensus Guidelines on the management of respiratory distress syndrome - 2016 update," Neonatology, vol. 111, no. 2, pp. 107-125, 2017.

[13] S. Riskin-Mashiah, B. Reichman, D. Bader et al., "Populationbased study on antenatal corticosteroid treatment in preterm small for gestational age and non-small for gestational age twin infants," The Journal of Maternal-Fetal \& Neonatal Medicine, vol. 31, no. 5, pp. 553-559, 2017.

[14] G. Raba and J. Kotarski, "Evaluation of risk factors can help to predict preterm delivery within 7 days in women hospitalized for threatened preterm labour," The Journal of MaternalFetal \& Neonatal Medicine, vol. 29, no. 19, pp. 3142-3146, 2016.

[15] I. Igbinosa, F. A. Moore III, C. Johnson, and J. E. Block, "Comparison of rapid immunoassays for rupture of fetal membranes," BMC Pregnancy and Childbirth, vol. 17, no. 1, p. 128, 2017.

[16] G. U. Eleje, E. C. Ezugwu, A. C. Eke et al., "Accuracy of a combined insulin-like growth factor-binding protein-1/interleukin-6 test (Premaquick) in predicting delivery in women with threatened preterm labor," Journal of Perinatal Medicine, vol. 45, no. 8, pp. 915-924, 2017.

[17] L. Mešić Đogić, D. Mićić, F. Omeragić, R. Kovač, and S. Fazlagić, "IGFBP-1 marker of cervical ripening and predictor of preterm birth," Medicinski Glasnik, vol. 13, no. 2, pp. 118-124, 2016. 
[18] R. Tripathi, S. Tyagi, Y. M. Mala, N. Singh, N. B. Pandey, and P. Yadav, "Comparison of rapid bedside tests for phosphorylated insulin-like growth factor-binding protein 1 and fetal fibronectin to predict preterm birth," International Journal of Gynaecology and Obstetrics, vol. 135, no. 1, pp. 47-50, 2016.

[19] V. Berghella and G. Saccone, "Fetal fibronectin testing for prevention of preterm birth in singleton pregnancies with threatened preterm labor: a systematic review and metaanalysis of randomized controlled trials," American Journal of Obstetrics \& Gynecology, vol. 215, no. 4, pp. 431-438, 2016.

[20] M. Kekki, T. Kurki, T. Kärkkäinen, V. Hiilesmaa, J. Paavonen, and E. M. Rutanen, "Insulin-like growth factor-binding protein-1 in cervical secretion as a predictor of preterm delivery," Acta Obstetricia et Gynecologica Scandinavica, vol. 80, no. 6, pp. 546-551, 2001.

[21] A. C. Holloway, A. Salomon, M. J. Soares et al., "Characterization of the adverse effects of nicotine on placental development: in vivo and in vitro studies," American Journal of Physiology-Endocrinology and Metabolism, vol. 306, no. 4, pp. E443-E456, 2014.

[22] R. B. Huang and O. Eniola-Adefeso, "Shear stress modulation of IL-1 $\beta$-induced E-selectin expression in human endothelial cells," PLoS One, vol. 7, no. 2, article e31874, 2012.

[23] X. Xiao, D. D. Mruk, and C. Y. Cheng, "Intercellular adhesion molecules (ICAMs) and spermatogenesis," Human Reproduction Update, vol. 19, no. 2, pp. 167-186, 2013.

[24] P. J. Newman, M. C. Berndt, J. Gorski et al., "PECAM-1 (CD31) cloning and relation to adhesion molecules of the immunoglobulin gene superfamily," Science, vol. 247, no. 4947, pp. 1219-1222, 1990.

[25] H. G. Zhang, W. Guo, H. F. Gu et al., "Correlation of VCAM-1 expression in serum, cord blood, and placental tissue with gestational hypertension associated with fetal growth restriction in women from Xingtai Hebei, China," Genet Mol Res, vol. 15 , no. 3 .

[26] P. Laudanski, G. Raba, P. Kuc, A. Lemancewicz, R. Kisielewski, and T. Laudanski, "Assessment of the selected biochemical markers in predicting preterm labour," The Journal of Maternal-Fetal \& Neonatal Medicine, vol. 25, no. 12, pp. 2696-2699, 2012.

[27] P. Laudanski, A. Lemancewicz, P. Kuc et al., "Chemokines profiling of patients with preterm birth," Mediators of Inflammation, vol. 2014, Article ID 185758, 7 pages, 2014.

[28] R. Czajka, A. Torbe, R. Rzepka, and M. Witczak, "Kliniczna analiza porodów przedwczesnych," Ginekologia Polska, vol. 71, no. 8, pp. 724-727, 2000.

[29] J. E. Shin, J. C. Shin, S. J. Kim, Y. Lee, I. Y. Park, and S. Lee, "Early midtrimester serum insulin-like factors and cervical length to predict preterm delivery," Taiwanese Journal of Obstetrics \& Gynecology, vol. 55, no. 1, pp. 45-49, 2016.

[30] C. M. Y. Chau, I. L. Cepeda, A. M. Devlin, J. Weinberg, and R. E. Grunau, "The Val66Met brain-derived neurotrophic factor gene variant interacts with early pain exposure to predict cortisol dysregulation in 7-year-old children born very preterm: implications for cognition," Neuroscience, vol. 342, pp. 188-199, 2017.

[31] L. Breiman, J. H. Friedman, R. A. Olshen, and C. J. Stone, Classification and Regression Trees, Chapman and Hall, Boca Raton, FL, USA, 1993.
[32] R. L. Goldenberg, A. R. Goepfert, and P. S. Ramsey, "Biochemical markers for the prediction of preterm birth," American Journal of Obstetrics \& Gynecology, vol. 192, no. 5, pp. S36-S46, 2005.

[33] J. A. Keelan, M. Blumenstein, R. J. A. Helliwell, T. A. Sato, K. W. Marvin, and M. D. Mitchell, "Cytokines, prostaglandins and parturition-a review," Placenta, vol. 24, Supplement A, pp. S33-S46, 2003.

[34] P. Laudanski, P. Pierzynski, and T. Laudanski, "Reductionist and system approaches to study the role of infection in preterm labor and delivery," BMC Pregnancy and Childbirth, vol. 7, Supplement 1, p. S9, 2007.

[35] M. R. Genc, S. S. Witkin, M. L. Delaney et al., "A disproportionate increase IL- $1 \beta$ over IL-1ra in the cervicovaginal secretions of pregnant women with altered vaginal microflora correlates with preterm birth," American Journal of Obstetrics \& Gynecology, vol. 190, no. 5, pp. 1191-1197, 2004.

[36] A. Nuytten, H. Behal, A. Duhamel et al., "Correction: evidence-based neonatal unit practices and determinants of postnatal corticosteroid-use in preterm births below 30 weeks GA in Europe. A population-based cohort study," PLoS One, vol. 12, no. 2, article e0172408, 2017. 


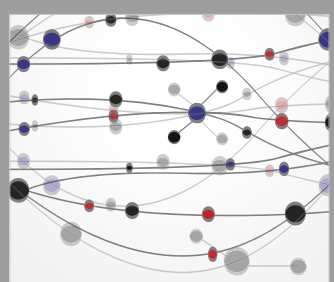

The Scientific World Journal
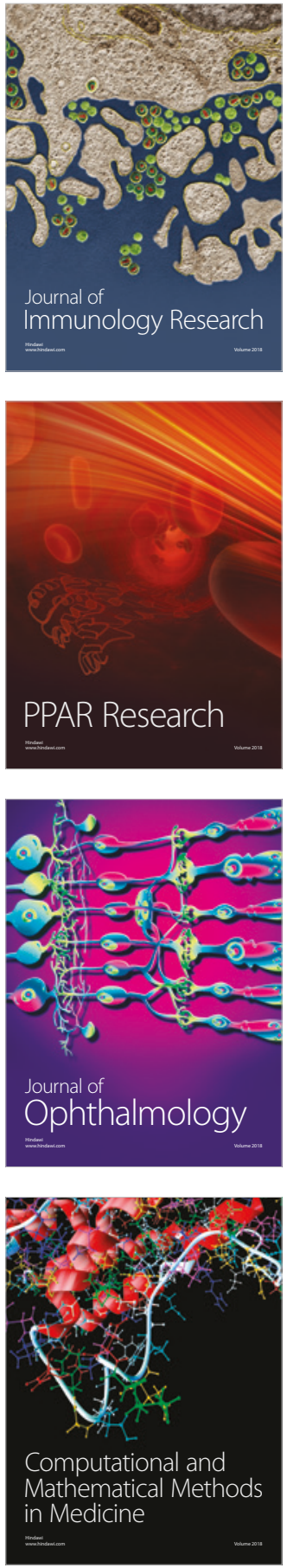

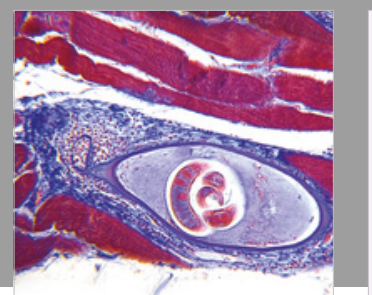

Gastroenterology Research and Practice



\section{Hindawi}

Submit your manuscripts at

www.hindawi.com


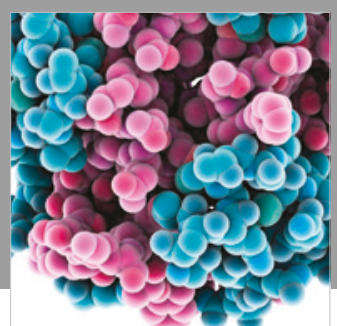

ournal of

Diabetes Research

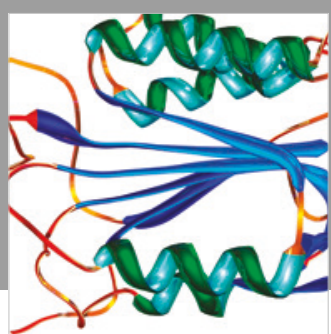

Disease Markers
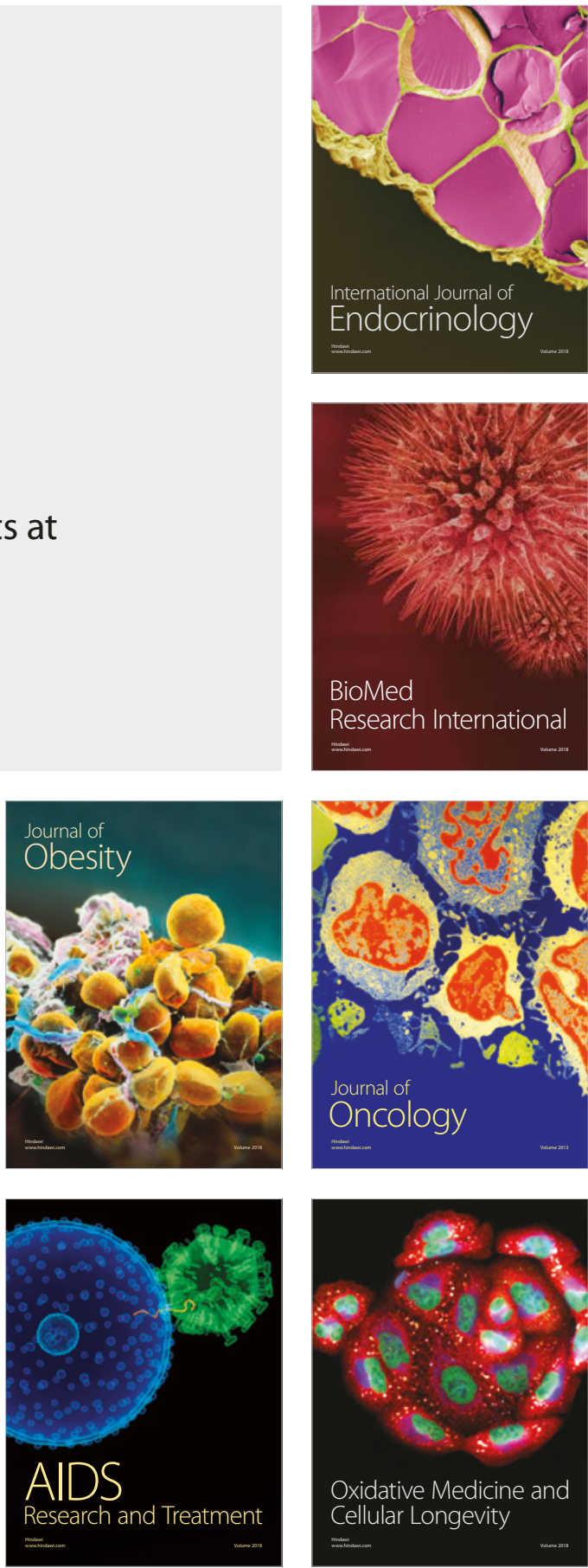